\title{
Colorimetric determination of carbohydrates in some brands of beer in Ghana as an indication of their glycemic index in the management of diabetes type II
}

\author{
Yaw Opoku Boahen and Antwi Isaac \\ Chemistry Department, University of Cape Coast, Cape Coast, Ghana \\ Corresponding author E-mail: yboahen@ucc.edu.gh, yawoboahen@yahoo.com
}

\begin{abstract}
There is worldwide campaign against the consumption of sugar said to be a possible cause of obesity and diabetes. The major sources of added sugars are regular soft drinks, beers, sugar candies, cakes, cookies, pies, fruit drinks, dairy desserts and milk products (ice cream, sweetened yogurt and sweetened milk), and other grains. The use of sugar in brewing is widespread and the consumption of beer is a matter of concern as one of the possible causes of diabetes type II. The 6 brands of beer produced in Ghana namely Guinness, Stone (produced from rice), Root Extra (produced from cassava), Star, Gulder, Club were therefore analysed for their total carbohydrate contents. The phenol-sulphuric acid method was employed and the absorbance was measured at $485 \mathrm{~nm}$. The total carbohydrate contents of the 6 beer samples expressed in terms of glucose ranged from the maximum of $34.58 \pm 1.5$ $\mathrm{g} / \mathrm{L}$ for Guinness equivalent to 15 cubes of sugar per litre to a minimum of $12.60 \pm 1.5 \mathrm{~g} / \mathrm{L}$ for Stone beer equivalent to 5 cubes of sugar per litre. The average value of $23.30 \pm 0.3 \mathrm{~g} / \mathrm{L}$ was recorded for Root Extra beer which was equivalent to 10 cubes of sugar per litre. The other brands namely, Star, Gulder and Club had values $19.01 \pm 1.4 \mathrm{~g} / \mathrm{L}, 22.10 \pm 0.5 \mathrm{~g} / \mathrm{L}$ and $24.05 \pm 2.7 \mathrm{~g} / \mathrm{L}$ equivalent to $8.5,9.6$ and 10.5 cubes of sugar per litre respectively. The amounts of carbohydrates in the 6 brands of beer investigated though variable were too high and could cause significant increase in glycemic index leading to poor control of blood glucose levels in people with diabetes type II conditions.
\end{abstract}

Keywords: Carbohydrate, absorbance, beer, glucose, glycemic index, diabetes

\section{INTRODUCTION}

The brewing industry forms a very significant part of the manufacturing sector of the economy in terms of the enormous contribution that the brewing supply chain makes to the national revenue. It is a long chain with good jobs on offer and taxes to be hauled in from the farmers, suppliers of fertilizers and farm equipments, brewers,distributors and retailers as well as shareholders and the hospitality industries.

The use of sugar in the brewery industry is widespread. In Ghana the two breweries namely:Accra Brewery (ABL) and Guinness Ghana Breweries Limited (GGBL) together produce about 6 brands of beer which are well patronized by Ghanaians on all occasions. The brands are Star, Gulder, Club, Root Extra (produced from cassava), Guinness and Stone beer (produced from rice). The consumption of sugar though arguable has been implicated as one of the causes of obesity and diabetes.The carbohydrate contents in beer are of concern because of their high glycemic index and the risk they pose to people with type II diabetic conditions who patronize these beverages. Poor control of blood glucose in patients with type II diabetes is the cause of diabetic retinopathy that leads to blindness. Other symptoms of diabetes include tingling in the hands and feet, reduced 
resistance to infections (boils, urinary tract infections and fungus vaginal infections), blurred vision caused by excess glucose in the fluid of the eye and impotence in men or absence of menstrual periods in women. Certain microorganisms are attracted to the sugary urine, and these agents can cause various complications, such as bladder infections and other urinary infections. Other complications which usually occur 15 to 20 years after onset of the disease include peripheral neuropathy, a nerve disease and chronic kidney failure (Clayman, 1994)

People with diabetes also run the risk of developing atherosclerosis with its risks of stroke, heart attack and high blood pressure. The blood vessels to your legs become narrowed, which can cause cramps, cold feet, pain, skin ulcers and gangrene. Ulcers on the leg fail to heal, rot and become very offensive leading to amputation of the leg among others (Clayman, 1994).

Urinating much more than usual, sometimes as often as every hour throughout the day and night is a symptom of diabetes. The excessive loss of fluid leads to unusual thirst and drinking of beer and sweetened beverages increases the amount of urination and makes the thirst worse. The cells do not get enough glucose leading to tiredness, weakness and apathy .

Consequently the carbohydrate contents in the 6 brands of beer available in Ghana were determined to give an indication of their glycemic index (GI) in order to inform the public and create awareness so as to regulate the intake of sugar containing beer that could pose a risk to obesity and diabetes.

\section{MATERIALS AND METHODS}

\section{Theory}

The Phenol -Sulphuric Acid method is an example of a colometric method that is widely used to determine the total concentration of carbohydrates present in foods. The determination of carbohydrate by the phenolsulphuric acid method, often called the Molisch's test depends on dehydration of hydrolysed saccharides to furfural derivatives in reaction with concentrated sulphuric acid. Further reaction of the furfural derivative with phenol forms coloured complexes that absorb light in the visible range with maximum absorbance at $485 \mathrm{~nm}$ (Pavia, Lampman and Kriz 1998, Gerchakov and Hatcher,1972, Dubois et al, 1956). The other phenolic compounds that have been used in this test are a-naphtol, thymol and resorcinol and the colour of the dye depends on the type of phenol employed(Figure 1).

\section{Collection of Samples}

The various brands of beer were all obtained from the market at the University of Cape Coast campus in May 2015

\section{Materials}

The materials were prepared as reported in the literature. Phenol solution-25g of phenol (A.R. NORMAPUR, BDH, PROLABO, VWR, Leuven, Belgium) was dissolved in $400 \mathrm{~mL}$ of water and diluted to make $500 \mathrm{~mL}$ of solution (Gerchakov and Hatcher, 1972)

Glucose stock solution-10 mg of $\beta$-D glucose anhydrous (A.R, Park Scientific, Northampton, U. K) was dissolved in $80 \mathrm{ml}$ of water and diluted to make $100 \mathrm{~mL}$ of stock solution $(100 \mu \mathrm{g} / \mathrm{mL})($ Gerchakov and Hatcher, 1972).

\section{Analytical Procedure}

Glucose Standards-Aliquots of $1 \mathrm{~mL}, 2 \mathrm{~mL}, 3 \mathrm{ml}, 4 \mathrm{~mL}$, $5 \mathrm{~mL}, 8 \mathrm{~mL}, 10 \mathrm{~mL} 13 \mathrm{~mL}$ and $20 \mathrm{~mL}$ of the glucose stock solution were pipetted and transferred into nine $30 \mathrm{~mL}$ beakers. Adequate amount of distilled water was added to make a final volume of $20 \mathrm{~mL}$. Each solution $(2 \mathrm{~mL})$ was measured and transferred into 10 test tubes. The phenol $(2 \mathrm{~mL})$ and $10 \mathrm{~mL}$ of the concentrated $96 \%$ sulphuric acid $\left(\mathrm{H}_{2} \mathrm{SO}_{4}\right)$ were pipetted and added to each of the 10 test tube. A light orange colour developed and was allowed to stand for $10 \mathrm{mins}$. The solutions were then transferred into $1-\mathrm{cm}$ path length cuvettes and the absorbances were measured at $485 \mathrm{~nm}$ with a UV spectrophotometer (SHIMADZU Mini-1240 UV-VIS model). Measurements were in triplicate and the average was determined. Reference solution was prepared in identical manner except that the $2 \mathrm{~mL}$ glucose solution was replaced with distilled water (Table 1). A standard curve of absorbance versus glucose concentration was drawn (Figure 2)

\section{Analysis of beer samples}

Star beer $(1 \mathrm{~mL})$ was measured and transferred into $1 \mathrm{~L}$ volumetric flask. Distilled water was added to make $1000 \mathrm{~mL}$ solution. Aliquot $(2 \mathrm{~mL})$ was transferred into a test tube and was mixed with $2 \mathrm{~mL}$ phenol solution and $10 \mathrm{~mL}$ concentrated sulphuric acid. The light orange colour developed and the absorbance was measured at $485 \mathrm{~nm}$ after $10 \mathrm{mins}$. Measurement was in triplicate and average determined. The procedure was repeated for the other 5 beer samples, namely Club, Guinness, Gulder, Root Extra and Stone.

\section{Analysis of sugar sample}

In a similar experiment three different cubes of sugar were randomly selected and weighed to give an average weight of $5.1930 \mathrm{~g}$. The cube of sugar was ground into granules and $6 \mathrm{mg}$ was dissolved in $80 \mathrm{ml}$ of distilled water and was diluted with distilled water to make $100 \mathrm{ml}$ 


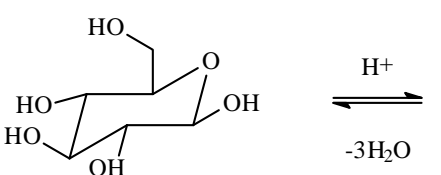

D-glucose<smiles>O=Cc1ccc(CO)o1</smiles>

5-hydroxymethyl furfural

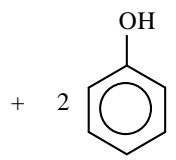

Phenol<smiles>O=Cc1ccc(CO)o1</smiles>

5-hydroxymethyl furfural

Figure 1.The Molisch's test.

solution in a volumetric flask. Aliquot $(2 \mathrm{~mL})$ of the sugar solution was transferred into a test tube and mixed with $2 \mathrm{~mL}$ phenol solution and $10 \mathrm{~mL}$ of concentrated sulphuric acid. The absorbance at $485 \mathrm{~nm}$ was measured after 10 mins. Measurement was in triplicate and average determined. It was determined that the total carbohydrate content of one cube of sugar $(5.1930 \mathrm{~g})$ in terms of glucose was $2.23 \mathrm{~g} / \mathrm{L}$.

\section{RESULTS AND DISCUSSION}

\section{Variability and Reliability of Statistical data}

The mean standard deviations (SD) and coefficient of variations (CV) of the calculated amount of glucose in the samples are reported in Table 2 (Harris, 1997). The percentage coefficient of variation was generally low indicating that the Beer Lambert law was obeyed to a large extent. The results in Table 2 and Figure. 2 clearly indicated a strong linear correlation between the carbohydrate contents and the absorbance.

The statistical significant variability among the various samples in terms of standard deviation $( \pm 2.7)$ and \% CV $(6 \%)$ was probably the result of slight inconsistencies in the colouration of furfural deviation by the phenol. The very high coefficient of determination R2 $=0.9914$ of the regression fits was an indication of the precision of the model for determining absorbance for a given glucose concentration.

To determine how standard deviation provides a measure of variability and reliability of the data, tests were done to find out how many measurements were within 1 standard deviation of the mean using the Chesbyshev theorem [(1-1/K2) x100] and the empirical rule ( $\Pi \pm s$ ) (Shafer, 2012). In all the samples $2 / 3$ measurements representing $66.7 \%$ were in the interval of $(\Pi \pm s)$ for the samples. This value indicated that there was slight significant variability. This slight percentage of the variability of standard deviation and the small range for each measurement obtained for all the samples gave an indication that the method was reliable for the determination of the total carbohydrate content.

\section{Analysis of total carbohydrate contents}

The four (4) basic materials for brewing are barley(malt), water, hops and yeast. Materials such as sugar, maize, rice, potato and sorghum have been employed. In Ghana the new addition has been the introduction of cassava in brewing. The use of sugar in the brewing is the norm in Ghana. The two breweries in Ghana use sugar or its derivatives in brewing their beers. No brewery in Ghana can claim not to add sugar at a point in their process. Sugar in the brewing process gives a higher yield of product, facilitates ease with which yeast ferments the brew and also improves the colour of the beer (Joe Fraser, 2015). The brewery companies are themselves mindful about the high levels of sugar in beer hence the introduction of "No added sugar" beer on the Ghanaian market. No added sugar Star beer as advertised has $25 \%$ less calories.

Table 2 shows the total carbohydrate contents in terms of glucose in the various brands of beer on the Ghanaian market. The various brands of beer namely: Stone, Star, Gulder, Root Extra, Club and Guinness are in the order of their glucose content as obtained from the analysis.

The total carbohydrate contents of the 6 beer samples expressed in terms of glucose ranged from the maximum of $34.58 \pm 1.5 \mathrm{~g} / \mathrm{L}$ for Guinness equivalent to 15 cubes of sugar per litre to a minimum of $12.60 \pm 1.5 \mathrm{~g} / \mathrm{L}$ for Stone 
Table 1. Concentration of Glucose Standards and Absorbances at $485 \mathrm{~nm}$.

\begin{tabular}{|c|c|c|c|c|c|c|}
\hline $\begin{array}{l}\text { Vol. of glucose. } \\
\text { standard. } \\
\text { solution (mL) }\end{array}$ & $\begin{array}{l}\text { Vol. of } \\
\text { water }(\mathrm{mL})\end{array}$ & $\begin{array}{l}\text { Conc.ofglu } \\
\text { cose } \\
\text { ( } \mathrm{sg} / \mathrm{mL})\end{array}$ & $A_{1}$ & $A_{2}$ & $A_{3}$ & $\mathrm{~A}=\frac{A_{1}-A_{2}+A_{2}}{j}$ \\
\hline 0 & 20 & 0 & 0.0004 & 0.0028 & -0.0032 & 0.0000 \\
\hline 2 & 18 & 10 & 0.1931 & 0.0737 & 0.0785 & 0.1151 \\
\hline 3 & 17 & 15 & 0.1705 & 0.1246 & 0.1400 & 0.1030 \\
\hline 4 & 16 & 20 & 0.2229 & 0.1848 & 0.2354 & 0.2143 \\
\hline 9 & 11 & 45 & 05344 & 0.4301 & 0.1474 & 0.4606 \\
\hline 10 & 10 & 50 & 0.5992 & 0.4963 & 0.4877 & 0.5277 \\
\hline 13 & 7 & 65 & 0.6392 & 0.6182 & 0.6455 & 0.6343 \\
\hline 20 & 0 & 100 & 0.9402 & 0.9496 & 0.9333 & 0.9410 \\
\hline
\end{tabular}

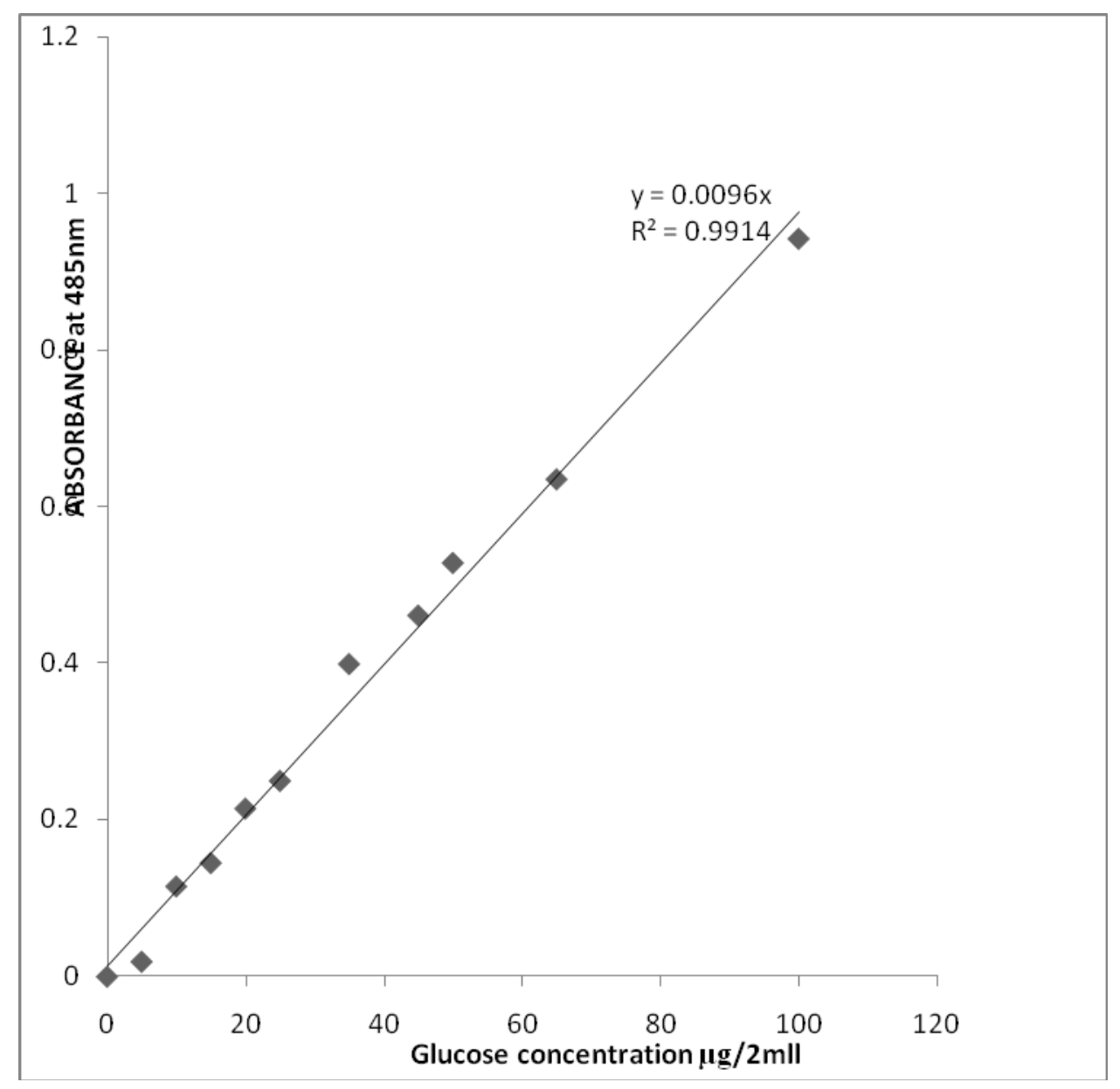

Figure 2. Calibration curve for glucose standard

beer equivalent to 5 cubes of sugar per litre. The average value of $22.10 \pm 0.5 \mathrm{~g} / \mathrm{L}$ was recorded for Root Extra beer which was equivalent to 10 cubes of sugar per litre. The other brands namely, Star, Gulder and Club had values $19.03 \pm 1.4 \mathrm{~g} / \mathrm{L}, \quad 22.30 \pm 0.5 \mathrm{~g} / \mathrm{L}, \quad$ and $24.05 \pm 2.7 \mathrm{~g} / \mathrm{L}$ equivalent to $8.5,9.6$ and 10.5 cubes of sugar per litre respectively. These results were in agreement with International Breweries Association standards which indicate that the total carbohydrates in beer typically range from a low value of $5 \mathrm{~g} / \mathrm{L}$ to a high value of $60 \mathrm{~g} / \mathrm{L}$ 
Table 2. The Absorbances and glucose concentrations of the 6brands of beer in Ghana.

\begin{tabular}{|c|c|c|c|c|c|c|c|c|}
\hline \multirow[t]{2}{*}{ Sample } & \multicolumn{2}{|c|}{ Absorbances } & tion & \multirow[t]{2}{*}{\begin{tabular}{ll}
\multicolumn{1}{c}{ Mean $\quad(\mathrm{ug}$} \\
Glucose $I 2 \mathrm{ml}$ \\
solution) \pm SD
\end{tabular}} & \multirow[t]{2}{*}{ CV } & \multirow[t]{2}{*}{$\begin{array}{l}\text { ST } \\
\text { Error }\end{array}$} & \multirow[t]{2}{*}{$\begin{array}{l}\text { Amt of glucose in } \\
\text { beer samples } \\
\text { (g/L) }\end{array}$} & \multirow[t]{2}{*}{$\begin{array}{l}\text { Equivalent No. } \\
\text { of cubes of } \\
\text { sugar in } 1 \mathrm{~L} \text { of } \\
\text { sample }\end{array}$} \\
\hline & 1 & II & III & & & & & \\
\hline Stone & $\begin{array}{l}0.2261 \\
23.6\end{array}$ & $\begin{array}{l}0.2241 \\
23.3\end{array}$ & $\begin{array}{l}0.2500 \\
26.0\end{array}$ & $24.30 \pm 1.5$ & 6 & 0.9 & 12.60 & 5 \\
\hline Star & $\begin{array}{l}0.3629 \\
37.8\end{array}$ & $\begin{array}{l}0.3536 \\
36.8\end{array}$ & $\begin{array}{l}0.3800 \\
39.6\end{array}$ & $38.06 \pm 1.4$ & 4 & 0.8 & 19.03 & 8.5 \\
\hline Gulder & $\begin{array}{l}0.4296 \\
44.8\end{array}$ & $\begin{array}{l}0.4177 \\
43.8\end{array}$ & $\begin{array}{l}0.4260 \\
44.4\end{array}$ & $44.33 \pm 0.5$ & 1 & 0.3 & 22.10 & 9.6 \\
\hline $\begin{array}{l}\text { Root } \\
\text { Extra }\end{array}$ & $\begin{array}{l}0.4432 \\
46.2\end{array}$ & $\begin{array}{l}0.4471 \\
46.3\end{array}$ & $\begin{array}{l}0.4489 \\
46.8\end{array}$ & $46.43 \pm 0.3$ & 0.6 & 0.2 & 23.30 & 10 \\
\hline Club & $\begin{array}{l}0.4375 \\
45.6\end{array}$ & $\begin{array}{l}0.4471 \\
46.3\end{array}$ & $\begin{array}{l}0.4713 \\
49.1\end{array}$ & $48.10 \pm 2.7$ & 6 & 1.6 & 24.05 & 10.5 \\
\hline Guinness & $\begin{array}{l}0.6671 \\
69.5 \\
\end{array}$ & $\begin{array}{l}0.4471 \\
46.3 \\
\end{array}$ & $\begin{array}{l}0.6770 \\
70.5 \\
\end{array}$ & $69.16 \pm 1.5$ & 2 & 0.9 & 34.58 & 15 \\
\hline
\end{tabular}

SD: Standard deviation, CV : Coefficient of variation

equivalent to one cube and 12 cubes of sugar/L respectively (Everitt, 2015).

High intakes of dietary sugars in the setting of a worldwide pandemic of obesity and cardiovascular disease have heightened concerns about the adverse effects of excessive consumption of sugars. The American Heart Association (AHA) recommends reductions in the intake of added sugars. A prudent upper limit of intake is half of the discretionary calorie allowance, which for most women is no more than 100 calories $(25 \mathrm{~g}, 3$ level teaspoonful, one level tables poonful, 5 cubes) per day and for most men is no more than 150 calories( $37 \mathrm{~g}, 4.5$ level teaspoonful, 1.5 level tablespoonful 6 cubes) per day from added sugars (Johnson et al, 2009).

The amount of sugar in the 6 brands of beer produced in Ghana as indicated in the analysis is too high. It cannot be an understatement that the two breweries in Ghana use sugar or its derivative-and lot of it too- in brewing their beers. The slogan "No added sugar' could therefore be a public deception. The high amount of sugar in beer is not limited to Ghana but is a worldwide phenomenon. Breweries in Ghana cannot therefore be solely responsible for the high sugar content in their products.

Though the adverse health effect of beer as a contributor to glycemic index is arguable, moderation should be the watch word for consumers especially people with diabetic conditions.

\section{CONCLUSION}

The sugar contents in the six brands of beer manufactured in Ghana have high sugar contents.

The values are however within the acceptable limits for beer worldwide. The sugar contents of beer produced worldwide can therefore contribute to their glycemic index and pose a risk to people with diabetic conditions.

\section{REFERENCES}

Clayman CB(1994), Family Medical Guide,( $3^{\text {rd }}$ ed). Random House Inc, New York, N. Y American Medical Association

Dubois M, Gilles KA, Hamilton JK, Rebers PA, Smith F(1956) Colorimetric Method for Determination of Sugars and related Substances,Anal. Chem., 28, 350-356

Everitt $\mathrm{R}(2015)$, Creating a Community: Build a Brewpub Loyalty Programme Retrieved August, 2015 from http://www.brewersassociation.org/category/articles/

Fraser J(2015, March 7) Why add sugar to my beer? Daily Graphic (No. 19710), page 7

Gerchakov SM, Hatcher PG(1972),Improved technique for analysis of Carbohydrates in Sediment,LimnolOceangr, 17(6), 938-943

Harris DC(1997), Exploring Chemical Analysis, Freeman and Company, New York

Johnson RK, Appel LJ, Brands M, Howard BV, Lefevre M, Lustig $\mathrm{RH}(2009)$ Dietary sugars intake and cardiovascular health: a scientific statement from the American Heart Association (Electronic version), Circulation,J. American Heart Association Retrieved August, 18, 2015, from http://www.heart.org/HEARTORG/

Pavia D, L.,Lampman GM, Kriz GS(1998). Organic Laboratory Techniques: Small Scale Approach,Harcourt Brace \& Company, Orlando, Florida, USA

Shafer DS, Zhang Z(2012), Begging of Statistics,(Vol.2), Flatworld Knowledge, Washsington, USA 